\title{
The Influence of Interfacial Roughness on Fiber Sliding In Oxide Composites with La-Monazite Interphases
}

\author{
J. B. Davis, ${ }^{*}$ R. S. Hay, ${ }^{* *}$ D. B. Marshall,* P.E.D. Morgan* \\ and A. Sayir*** \\ *Rockwell Scientific \\ 1049 Camino Dos Rios \\ Thousand Oaks, CA 91360 \\ ** Air Force Research Laboratory \\ Materials Directorate \\ WPAFB, OH 45433 \\ ***NASA Glenn Research Center / CWRU \\ NASA Glenn Research Center \\ 21000 Brookpark Road \\ Cleveland, $\mathrm{OH} 44135$
}

\section{ABSTRACT}

Room temperature debonding and sliding of La-monazite coated fibers is assessed using a composite with a polycrystalline alumina matrix and fibers of several different single crystal (mullite, sapphire) and directionally solidified eutectic $\left(\mathrm{Al}_{2} \mathrm{O}_{3} / \mathrm{Y}_{3} \mathrm{Al}_{5} \mathrm{O}_{12}\right.$ and $\mathrm{Al}_{2} \mathrm{O}_{3} / \mathrm{Y}-\mathrm{ZrO}_{2}$ ) compositions. These fibers provide a range of residual stresses and interfacial roughnesses. Sliding occurred over a debond crack at the fiber-coating interface when the sliding displacement and surface roughness were relatively small. At large sliding displacements with relatively rough interfaces, the monazite coatings were deformed extensively by fracture, dislocations and occasional twinning, whereas the fibers were undamaged. Dense, fine-grained $(10 \mathrm{~nm})$ microstructures suggestive of dynamic recrystallization were also observed in the coatings. Frictional heating during sliding is assessed. The possibility of low temperature recrystallization is discussed in the light of the known resistance of monazite to radiation damage. The ability of Lamonazite to undergo plastic deformation relatively easily at low temperatures may be enabling for its use as a composite interface. 


\section{INTRODUCTION}

Rare-earth orthophosphates (monazite and xenotime) are of interest for fiber-matrix interphases that enable interfacial debonding and damage tolerance in oxide composites. ${ }^{1-11}$ They are refractory materials $\left(\mathrm{LaPO}_{4}\right.$ melting point $\left.2070^{\circ} \mathrm{C}\right){ }^{12}$ compatible in high temperature oxidizing environments with many oxides that are either currently available as reinforcing fibers or of interest for future development as fibers and matrices. They are also relatively soft for such refractory materials $\left(\mathrm{LaPO}_{4}\right.$ hardness $\left.5 \mathrm{GPa}\right){ }^{1}$ Studies of several combinations of oxides and rare-earth phosphates $\left(\mathrm{LaPO}_{4}-\mathrm{Al}_{2} \mathrm{O}_{3}\right.$, $\mathrm{LaPO}_{4}-\mathrm{ZrO}_{2}, \mathrm{CePO}_{4}-\mathrm{ZrO}_{2}, \mathrm{YPO}_{4}-\mathrm{Al}_{2} \mathrm{O}_{3}$ and $\mathrm{NdPO}_{4}-\mathrm{Al}_{2} \mathrm{O}_{3}$ ) have shown that the oxidephosphate interfacial bond is sufficiently weak that debonding occurs whenever a crack approaches an interface from within the phosphate. ${ }^{1,13-15}$ The most detailed studies have involved the $\mathrm{LaPO}_{4}-\mathrm{Al}_{2} \mathrm{O}_{3}$ system. Other studies have shown that debonding and sliding occurs in fiber push-out tests with model composites consisting of $\mathrm{LaPO}_{4}$-coated single crystal fibers of $\mathrm{Al}_{2} \mathrm{O}_{3}$ and $\mathrm{Y}_{3} \mathrm{Al}_{5} \mathrm{O}_{12}$ (YAG) in polycrystalline $\mathrm{Al}_{2} \mathrm{O}_{3}$ matrices. ${ }^{1,16}$

Damage-tolerant behavior in ceramic composites requires sliding and pullout of fibers in addition to interfacial debonding. Recent calculations suggest that such pullout would be strongly suppressed in fully dense oxide composites by misfit stresses generated during sliding of fibers with rough interfaces or with minor fluctuations in diameter. ${ }^{17}$ For given strain mismatch, these misfit stresses are expected (assuming elastic accommodation) to be larger in oxide interphase composites than in composites with turbostratic carbon or boron nitride interphases which have low transverse elastic modulus. However, the misfit stresses could potentially be reduced by plastic deformation of the interphase. The 
higher elastic modulus in oxide interphases also causes larger residual thermal stresses in systems with matrix and fibers of different thermal expansion coefficients.

In this study, we investigate the debonding and sliding behavior of four La-monazite coated fibers (single-crystal alumina and mullite, directionally solidified eutectics of $\mathrm{Al}_{2} \mathrm{O}_{3} / \mathrm{YAG}$ and $\mathrm{Al}_{2} \mathrm{O}_{3} / \mathrm{Y}^{-} \mathrm{ZrO}_{2}$ ), chosen to provide different residual stress states and interface topology. The coated fibers were surrounded with a matrix of polycrystalline $\mathrm{Al}_{2} \mathrm{O}_{3}$. Debonding and sliding were assessed using indentation fracture and push-out techniques. Damage in the coating, including plastic deformation, was identified by scanning and transmission electron microscopy (SEM and TEM).

\section{EXPERIMENTAL}

Four different single crystal or directionally solidified eutectic oxide fibers, grown at NASA Glenn by a laser-heated float zone technique, ${ }^{18,19}$ were coated with $\mathrm{LaPO}_{4}$ by dipping in a slurry of rhabdophane (hydrated $\mathrm{LaPO}_{4}$ ). The coated fibers were embedded in $\alpha$-alumina powder (Sumitomo AKP50) and hot pressed in graphite dies for $1 \mathrm{~h}$ at $1400^{\circ} \mathrm{C}$. Uncoated fibers were included in the same specimen for reference. The fibers were arranged in rows within the one hot-pressed disk, with separation between fibers $\sim 2$ $\mathrm{mm}$, thus ensuring identical processing conditions for all fibers. In an earlier study, the same rhabdophane slurry yielded pure La-monazite, with no excess La or P being detectable either by EDS analysis of the monazite or by reaction of the monazite with sapphire fibers after long-term heat treatment $\left(200 \mathrm{~h}\right.$ at $\left.1600^{\circ} \mathrm{C}\right) .^{3}$ 
The fibers had different surface textures and thermal expansion coefficients, thus allowing assessment of the effects of interfacial topology and residual stress on debonding and sliding mechanisms. The fibers were as follows:

(1) Directionally solidified $\mathrm{Al}_{2} \mathrm{O}_{3} / \mathrm{ZrO}_{2}$ eutectic fibers with a two-phase microstructure of alumina and cubic zirconia (stabilized with $\mathrm{Y}_{2} \mathrm{O}_{3}$ ). ${ }^{20}$ Dimensions of the individual phases were $\sim 0.5 \mu \mathrm{m}$. The starting composition of the feed rod was 60.8 mole $\% \mathrm{Al}_{2} \mathrm{O}_{3} ; 39.2$ mole $\% \mathrm{ZrO}_{2}\left(9.5\right.$ mole $\left.\left.\% \mathrm{Y}_{2} \mathrm{O}_{3}\right)\right)$ with purity levels $99.995 \%$ or better. X-ray and SEM/TEM analysis did not show any evidence for a third phase, indicating that all of the $\mathrm{Y}_{2} \mathrm{O}_{3}$ was in solid solution in the $\mathrm{ZrO}_{2}$. The surfaces of the fibers were rough on the scale of the microstructure (Fig. 1(a)). The fiber diameters were $\sim 100 \mu \mathrm{m}$ with fluctuations of $\sim 2 \mu \mathrm{m}$ over lengths of $\sim 200 \mu \mathrm{m}$. Thermal mismatch during cooling of the composite caused tensile radial stresses normal to the fiber surface (Table1).

(2) Directionally solidified $\mathrm{Al}_{2} \mathrm{O}_{3} / \mathrm{YAG}$ eutectic fibers, ${ }^{21}$ with a two-phase microstructure of dimensions $\sim 0.5 \mu \mathrm{m}$ and surface roughness on the scale of the microstructure (Fig. 1(b)). The fiber diameters were $\sim 100 \mu \mathrm{m}$, with fluctuations of $<1 \mu \mathrm{m}$ over lengths of $\sim 1$ $\mathrm{mm}$. Thermal mismatch stresses were of the same sign as for the $\mathrm{Al}_{2} \mathrm{O}_{3} / \mathrm{ZrO}_{2}$ fibers but were smaller in magnitude (Table 1).

(3) Mullite single-crystal fibers formed from a source rod of high purity $(99.99 \%)$ polycrystalline alumina powder (CERAC) and $99.99 \%$ pure $\mathrm{SiO}_{2}$ (Alpha Products), which gave 2:1 mullite as described in Ref. 19. In the as-grown condition the fibers had smooth surfaces but relatively large fluctuations in diameter $(50 \pm 5 \mu \mathrm{m}$, Fig. 1 (c)) with period $\sim 100 \mu \mathrm{m}$. Thermal mismatch caused large compressive radial stress in the 
coating and at the fiber-coating and coating-matrix interfaces, with tensile circumferential stress in the coating and matrix (Table1).

(4) Sapphire fibers, which had smooth surfaces (as-grown) and relatively uniform diameter $(100 \pm 1 \mu \mathrm{m})$. These were included for comparison with previous studies of this system. ${ }^{1,3}$ All residual stresses except the circumferential (and axial) tension in the coating are small.

TABLE 1 Representative* residual stresses in composites of monazite-coated fibers in polycrystalline $\mathrm{Al}_{2} \mathrm{O}_{3}$ matrix. Stresses in $\mathrm{MPa}$.

\begin{tabular}{lllll}
\hline \multirow{2}{*}{ Stress component } & \multicolumn{4}{c}{ Fiber } \\
\cline { 2 - 5 } & Sapphire & Mullite & $\mathrm{Al}_{2} \mathrm{O}_{3} / \mathrm{YAG}$ & $\mathrm{Al}_{2} \mathrm{O}_{3} / \mathrm{ZrO}_{2}$ \\
\hline Radial (coating/fiber) & 15 & -720 & 130 & 240 \\
Radial (matrix/coating) & 25 & -630 & 140 & 240 \\
Circumferential (coating) & 300 & 420 & 290 & 280 \\
Axial (fiber) & 7 & -1160 & 240 & 420 \\
\hline
\end{tabular}

*Values in this table are intended only as rough guide for relative stresses. They were calculated using a coaxial cylinder analysis, ${ }^{22}$ assuming a temperature change of $\Delta \mathrm{T}=1000^{\circ} \mathrm{C}$, coating thickness $2 \mu \mathrm{m}$, zero volume fraction of fibers, and the following Young's moduli and thermal expansion coefficients (nominal isotropic, temperature-independent values): polycrystalline $\mathrm{Al}_{2} \mathrm{O}_{3}\left(400 \mathrm{GPa}, 8 \times 10^{-6}{ }^{\circ} \mathrm{C}^{-1}\right)$; sapphire $(400$ $\left.\mathrm{GPa}, 8 \times 10^{-6}{ }^{\circ} \mathrm{C}^{-1}\right)$; mullite $\left(200 \mathrm{GPa}, 4 \times 10^{-6}{ }^{\circ} \mathrm{C}^{-1}\right) ; \mathrm{Al}_{2} \mathrm{O}_{3} / \mathrm{ZrO}_{2}\left(300 \mathrm{GPa}, 9 \times 10^{-6}{ }^{\circ} \mathrm{C}^{-1}\right)$; and $\mathrm{Al}_{2} \mathrm{O}_{3} / \mathrm{YAG}$ $\left.\left(350 \mathrm{GPa}, 8.5 \times 10^{-6}{ }^{\circ} \mathrm{C}^{-1}\right)\right)^{2 \cdot-25}$

The hot-pressed disk was cut into slices (thickness $\sim 0.3$ to $2 \mathrm{~mm}$ ) normal to the fibers. The surfaces of the slices were polished using diamond paste and some of the polished slices were thermally etched. The thicker slices were used for indentation cracking experiments, which involved placing Vickers indentations (10 $\mathrm{kg}$ load) in the 
polycrystalline alumina matrix near the fibers. The indenter was oriented so that one of the median/radial cracks grew towards the fiber to test for interfacial debonding. The thinner slices were used for fiber push-out experiments, which involved loading a flat punch (truncated Vickers indenter) onto the end of each fiber while the slice was supported in a fixture with a gap beneath the fiber. Some specimens were fractured after the push-out test to separate the debonded interface. The indented and pushed out specimens were examined by optical and scanning electron microscopy (SEM).

Specimens used for fiber push-out were also sectioned parallel and perpendicular to the fiber axes and examined by TEM (Phillips CM20 FEG operating at 200kV) to allow identification of damage within the $\mathrm{LaPO}_{4}$ coating caused by debonding and sliding. Four $\mathrm{Al}_{2} \mathrm{O}_{3} / \mathrm{YAG}$ fibers were examined in the parallel section; one mullite and one $\mathrm{Al}_{2} \mathrm{O}_{3} / \mathrm{ZrO}_{2}$ were examined in the axial section. The TEM foils were prepared by impregnating the specimens with epoxy, tripod polishing to thickness of $10 \mu \mathrm{m}$, followed by ion milling (Gatan model 691 operating at $4.5 \mathrm{kV}$ ). ${ }^{26}$

\section{RESULTS}

\subsection{Microstructural Observations}

All of the coated fibers were surrounded with a continuous layer of $\mathrm{LaPO}_{4}$ and a fully dense matrix of polycrystalline $\mathrm{Al}_{2} \mathrm{O}_{3}$. The coating thicknesses were nonuniform (between $\sim 1 \mu \mathrm{m}$ and $5 \mu \mathrm{m}$ ) and largest at the positions where the fiber surfaces were parallel to the hot pressing direction. No reactions were observed between the $\mathrm{LaPO}_{4}$ and any of the fibers. Occasionaliy an elongated La-magnetoplumbite $\left(\mathrm{LaAl}_{11} \mathrm{O}_{19}\right)$ grain was observed along the coating-matrix interface. Despite the presence of substantial tensile 
residual stresses in all of the $\mathrm{LaPO}_{4}$ coatings ( 300 to $400 \mathrm{MPa}$, table 1$)$, no evidence of cracking was detected by SEM examination of polished or thermally etched crosssections (although fine-scale through-thickness coating cracks were observed in thin TEM foils of other similar composites). The grain sizes were $\sim 0.5$ to $1 \mu \mathrm{m}$ in the monazite and $\sim 2$ to $10 \mu \mathrm{m}$ in the alumina matrix.

\subsection{Interfacial Debonding}

The $\mathrm{LaPO}_{4}$ coatings protected all of the fibers from penetration of indentation cracks, whereas uncoated fibers were always penetrated. Examples are shown for the $\mathrm{Al}_{2} \mathrm{O}_{3} / \mathrm{YAG}, \mathrm{Al}_{2} \mathrm{O}_{3} / \mathrm{ZrO}_{2}$ and mullite fibers in Figs. 2 to 4 . The indentation cracks generally extended from the matrix into the $\mathrm{LaPO}_{4}$ coatings then arrested and caused debonding at the coating/fiber interface. In a few cases with the $\mathrm{Al}_{2} \mathrm{O}_{3} / \mathrm{ZrO}_{2}$ fibers debonding occurred at both interfaces (matrix/coating and coating/fiber). The former response was observed previously with coated sapphire fibers and was shown to be consistent with the debond criterion of $\mathrm{He}$ and Hutchinson ${ }^{27}$ and the measured fracture toughnesses of the fibers, coating, and interface.' Although the fracture toughnesses of the YAG/ $\mathrm{LaPO}_{4}$ and mullite/ $\mathrm{LaPO}_{4}$ interfaces have not been measured, the present observations suggest that they are similar to that of the alumina/ $\mathrm{LaPO}_{4}$ interface $(\sim 4.5$

$\mathrm{J} / \mathrm{m}^{2}$ ). It is noteworthy that the fibers were protected from cracking even when the contact area of the Vickers indentation was close enough to the fiber to overlap the coating (Fig. 3(b)). In that case the residual stress from the indentation (compressive normal to the interface, tensile on the prospective crack plane into the fiber) would tend to inhibit debonding and favor fiber penetration. 
The interfacial roughnesses for both of the eutectic fibers were similar to the surface roughnesses of the as-formed fibers, with amplitude $\sim 100-300 \mathrm{~nm}$ and period $\sim 500 \mathrm{~nm}$ (Figs. 2(a) and 3(a)). This roughness amplitude is greater than that of the interfaces at the single-crystal mullite and sapphire fibers. These initially smooth fibers developed cusps during hot pressing where grain boundaries of the monazite coating intersected the fiber surface. Measurements of the cusp profiles on sapphire fibers by atomic force microscopy have been reported elsewhere. ${ }^{28.29}$ The cusp heights were typically $\sim 50 \mathrm{~nm}$ and the angular distortions of the surface were small $\left(\leq 20^{\circ}\right)$. The cusps on the mullite surfaces were very similar.

Some insight into the effect of interfacial roughness on fiber sliding and pullout can be gained from the observations of Figs. 2 to 4 . As the debond grows around the circumference of the fiber, the loading on the crack tip due to the indentation stress field is initially mostly shear (although the loading eventually changes to tension if the crack grows sufficiently). Since fiber pullout also involves shear loading of a debond crack, the initial region of growth of the deflected cracks in Figs. 2-4 should be representative of the behavior during the corresponding stage of pullout.

In all cases, the initial debond crack followed the fiber-matrix interface, even when the interface was rough. For the mullite fibers (Fig. 4) the sliding displacement of the debond crack surfaces ( $250 \mathrm{~nm}$, i.e., opening displacement of initial indentation crack) is smaller than the average spacing between the interfacial cusps $(\sim 600 \mathrm{~nm})$. Sliding caused separation of the debonded surfaces to accommodate their misfit (Fig. 4(b)), despite the constrained configuration with large residual compressive normal stress $(\sim$ $700 \mathrm{MPa}$, Table 1). The misfit was apparently accommodated by elastic strains, with no 
irreversible deformation of the mullite fiber or $\mathrm{LaPO}_{4}$ coating discernable by SEM. In contrast, sliding of the eutectic fibers caused extensive damage in the $\mathrm{LaPO}_{4}$ coating (Fig. 2 (c)), without discernable damage in the fibers. The damage included cracks across the full width of the coating, aligned at $\sim 45^{\circ}$ to the interface on planes of maximum tension, similar to previous observations of cracking in layers of $\mathrm{LaPO}_{4}$ sandwiched between polycrystalline $\mathrm{Al}_{2} \mathrm{O}_{3}{ }^{1}$. More intense local damage is evident at individual asperities, as in Fig. 2(c). The damage included cracking and fine lamellar features, which could be cracks or twins.

\subsection{Fiber Push-out}

All of the fibers debonded during the push-out experiments. Sliding occurred unstably over distances of $\sim 5$ to $10 \mu \mathrm{m}$ at a critical load between 10 and $20 \mathrm{~N}$. The average shear stress (load divided by fiber surface area) at the critical load was $130 \pm 10 \mathrm{MPa}$ for the sapphire fiber, $200 \pm 20 \mathrm{MPa}$ for the mullite fiber, $190 \pm 20 \mathrm{MPa}$ for the $\mathrm{Al}_{2} \mathrm{O}_{3} / \mathrm{YAG}$ fiber, and $255 \pm 30 \mathrm{MPa}$ for the $\mathrm{Al}_{2} \mathrm{O}_{3} / \mathrm{ZrO}_{2}$ fiber.

Sliding of the sapphire fiber occurred at the fiber-coating interface, as reported

previously. 'Grain boundary cusps were observed along the separated interfaces by SEM and AFM, although no damage was visible in either the fiber or the coating.

$\mathrm{Al}_{2} \mathrm{O}_{3} / \mathrm{YAG}$ and $\mathrm{Al}_{2} \mathrm{O}_{3} / \mathrm{ZrO}$ fibers

Extensive wear tracks were observed in the $\mathrm{LaPO}_{4}$ coating on both eutectic fibers, indicating that sliding involved plastic deformation (Fig. 5). The plane of sliding was mostly adjacent to the fiber-matrix interface, although smeared fragments of the $\mathrm{LaPO}_{4}$ 
coating remained on the fiber surface. In some regions (such as Fig. 5) sliding occurred near the matrix-coating interface.

TEM observations from a typical specimen containing a pushed-out $\mathrm{Al}_{2} \mathrm{O}_{3} / \mathrm{YAG}$ fiber are shown in Figs. 6-8. Sliding occurred along a debond crack between the $\mathrm{LaPO}_{4}$ coating and the fiber. In most regions a thin layer of the $\mathrm{LaPO}_{4}$ coating within $\sim 100$ to $300 \mathrm{~nm}$ of the fiber was heavily deformed (Figs. 6-8). The intensity of deformation decreased with distance from the debond crack, with regions more than $\sim 500 \mathrm{~nm}$ from the fiber being undeformed. The $\mathrm{Al}_{2} \mathrm{O}_{3} / \mathrm{YAG}$ fiber was also undamaged.

Deformation in the $\mathrm{LaPO}_{4}$ consisted of tangled dislocations, lamellar features resembling twins (Fig. 6), microcracks, and very fine crystallites of $\mathrm{LaPO}_{4}$ with diameter as small as $10 \mathrm{~nm}$ (Fig. 6b). The density of dislocations varied from grain to grain and generally decreased with distance from the debond crack. The fine crystallites were in regions within $\sim 50-100 \mathrm{~nm}$ of the debond crack and were suggestive of a recrystallized microstructure (Fig. 6-8). In one region there was no deformation on the monazite side of the debond crack, but a thin layer of dense fine-grained $(10 \mathrm{~nm})$ monazite was smeared on the fiber surface, again suggestive of recrystallization. In some areas this smeared layer was overlain by a less dense, coarser grained $(20 \mathrm{~nm})$ agglomeration of angular monazite particles, suggestive of cataclastic flow, a process involving repeated microfracture and fine particle transport. ${ }^{30}$ Similar features (intense deformation, fine crystallites, and agglomerates of angular particles) were observed in monazite debris (irregularly shaped balls, $\sim 100-500 \mathrm{~nm}$ diameter) in the debond crack. 
Sliding of the mullite fibers occurred predominantly at the fiber-matrix interface. SEM observations of separated interfaces showed plastic deformation of the $\mathrm{LaPO}_{4}$ coating where the varying fiber diameter caused compression of the coating during sliding, as depicted in region B of Fig. 9. (Note that the sliding displacements are smaller than the period of the diameter fluctuations and larger than the spacing of cusps associated with grain boundaries in the $\mathrm{LaPO}_{4}$ coating.) Where sliding caused tension across the coatingfiber interface (region A in Fig. 9), the separated interface was similar to that of the sapphire fiber, with grain-boundary cusps, clean separation, and no damage in the fiber or the coating.

Direct correlation of the changes in coating damage with fiber diameter fluctuation by TEM was difficult, because only limited areas were observed. Nevertheless, some trends are evident. Deformation was distributed, often non-uniformly, through the entire coating thickness (Figs. 10 and 11), rather than being localized in a thin layer adjacent to the fiber as for the $\mathrm{Al}_{2} \mathrm{O}_{3} / \mathrm{YAG}$ fiber. In some places the monazite adjacent to the fiber was undeformed, while in others plastic deformation was confined to an isolated grain (Fig. 10). The region of Fig. 10 was thought to have experienced tension during sliding (as in Region A, Fig. 9), although the correlation with fiber diameter is uncertain because some of the fiber adjacent to the debond crack was removed during ion-milling. Extensive microcracking was distributed throughout the coating, often at $+/-\sim 45^{\circ}$ to the fiber surface (Figs. 10 and 11).

In regions of coating inferred to have been compressed during sliding (as in region B of Fig. 9), almost the entire coating was microcracked and plastically deformed (Fig. 11). Extensive dislocation plasticity was evident, with variations in density from grain to 
grain. Some grains were twinned parallel to the fiber-matrix interface (Fig. 11), the orientation of maximum shear stress due to pushout of the fiber. Microcracking at $\sim 45^{\circ}$ to the fiber surface, was extensive, with crack spacings as small as $\sim 50 \mathrm{~nm}$ and an abundance of planar segments consistent with cleavage on (100), (010), and (001), as reported previously. ${ }^{31}$ There was some tendency for cracks oriented normal to the maximum tensile stress (NW to SE in Fig.11) to be longer and have greater opening displacements than other cracks; however, the trends are subjective, and could have been a sample preparation artifact.

\subsection{DISCUSSION}

\subsection{Effects of residual stress}

The residual stresses noted in Table 1 might be expected to influence interfacial debonding. Therefore, it is necessary to establish whether the fracture behavior in the model experiments reported here is representative of that in real composites, given the differences in residual stress states and crack orientations.

In the analysis of $\mathrm{He}$ et $\mathrm{al}^{32}$ the presence of residual stresses shifts the debond criterion by an amount that depends on the parameters $\eta_{\mathrm{p}}$ and $\eta_{\mathrm{d}}$ :

$$
\eta_{p}=\sigma_{p} a^{1 / 2} / K, \quad \eta_{d}=\sigma_{d} a^{1 / 2} / K
$$

where $\sigma_{p}$ and $\sigma_{d}$ are the residual stresses normal to potential crack paths along the interface or into the fiber, $\mathrm{K}$ is the applied stress intensity factor for the incident crack, and $\mathrm{a}$ is a defect size. For a crack approaching the fiber on a radial plane, as in the indentation cracking experiments of Sect. 3.2, the residual stresses $\sigma_{\mathrm{p}}$ and $\sigma_{\mathrm{d}}$ (radial and 
hoop stresses at the fiber surface) are equal, so the debond condition is not affected by the residual stresses.

For cracks oriented normal to the fiber axis (the most important case for a composite), $\sigma_{\mathrm{p}}$ is the axial stress in the fiber and $\sigma_{\mathrm{d}}$ is the radial stress at the fiber surface. The ratio of the axial to the radial stress is $\sim 2$ for all of the fibers (Table 1), both stresses being compressive for the mullite fibers and tensile for the others. Therefore, the residual stresses should favor debonding for mullite fibers and fiber penetration for both eutectic fibers. However, this result is sensitive to the volume fraction of fibers. For a fiber volume fraction of 0.5 , a typical value for structural composites, the magnitudes of the axial stresses decrease by a factor of $\sim 2$, to a level similar to the radial stresses. Then the residual stresses do not affect the condition for debonding and observations from cracks oriented as in the model indentation experiments are representative of transverse cracking in the composite. The additional influence of the residual stress field of the indentation, which favors penetration of the crack into the fiber, makes the indentation crack a conservative indicator for debonding.

\subsection{Effects of misfit stresses}

Misfit stresses were generated during fiber sliding by roughness at two length scales, one microstructural (grooves that form at intersections of grain boundaries in the monazite coating or lamellae boundaries of the eutectic fibers with the fiber/coating interface), and the other due to long-range fluctuations in fiber diameter (Fig. 1 and Table 2). Sliding displacements in the push-out experiments exceeded the microstructural dimensions by a factor of $\sim 5$ to 10 , but were smaller than the period of the diameter fluctuations by factors 
of $\sim 10$ to 100 . The microstructural roughness dominated the misfit strains for the eutectic fibers and sapphire fibers (Table 2).

For the mullite fibers, the superposition of misfit strains due to thermal expansion mismatch (Table 1) and diameter fluctuations (at the maximum sliding displacement) would cause compressive radial stresses as high as $5.2 \mathrm{GPa}$ in some regions and tension in others. Since this maximum compressive stress is higher than the hardness of $\mathrm{LaPO}_{4}$ $\left(5 \mathrm{GPa}^{\mathrm{l}}\right)$, plastic deformation should occur throughout the coating, as observed (Fig. 11).

TABLE 2. Misfit strains and stresses

\begin{tabular}{lllll}
\hline & \multicolumn{4}{c}{ Fiber } \\
\cline { 2 - 5 } & Sapphire & Mullite & $\mathrm{YAG} / \mathrm{Al}_{2} \mathrm{O}_{3}$ & $\mathrm{Al}_{2} \mathrm{O}_{3} / \mathrm{ZrO}_{2}$ \\
\hline Fiber radius $(\mathrm{R} / \mu \mathrm{m})$ & 50 & 25 & 50 & 50 \\
& & & & \\
Microstructural roughness & & & & \\
$\delta \mathrm{r}(\mu \mathrm{m})$ & 0.05 & 0.05 & 0.2 & 0.2 \\
$\lambda_{\mathrm{r}}(\mu \mathrm{m})$ & 2 & 2 & 1 & 1 \\
$\delta \mathrm{r} / \mathrm{R}$ & 0.001 & 0.002 & 0.004 & 0.004 \\
$\sigma_{\mathrm{r}}(\mathrm{MPa})^{* *}$ & -200 & -300 & -770 & -730 \\
Fiber diameter fluctuation & & & & \\
$\Delta \mathrm{R}(\mu \mathrm{m})$ & 0.5 & 2.5 & 0.5 & 1 \\
$\lambda_{\mathrm{R}}(\mu \mathrm{m})$ & 500 & 100 & 1000 & 400 \\
$(\Delta \mathrm{R} / \mathrm{R})\left(\pi \mathrm{Z}_{\max } / \lambda_{\mathrm{R}}\right)^{*}$ & 0.0006 & 0.03 & 0.0003 & 0.0015 \\
$\sigma_{\mathrm{R}}(\mathrm{MPa})^{* *}$ & -120 & -4500 & -60 & -270 \\
\hline
\end{tabular}

${ }^{*} \mathrm{z}_{\max }$ is the maximum sliding displacement $(\sim 10 \mu \mathrm{m})$

** Nominal radial misfit stresses intended only as rough guide for comparisons: stresses calculated as in Table 1 but with radial misfit strains $\delta r / R$ and $(\Delta R / R)\left(\pi z_{\max } / \lambda_{R}\right)$, the latter being the maximum misfit strain for sinusoidal diameter fluctuation.

For the other fibers the maximum radial mismatch due to fluctuations in fiber diameter is of similar magnitude and opposite sign to the thermal expansion mismatch. Therefore, 
deformation of the coating should depend on the microstructural roughness (both the roughness shape and the mismatch strain, $\delta \mathrm{r} / \mathrm{R}$ ). The single crystal fibers clearly had smaller microstructural mismatch strains $(\delta r / R<0.002)$ than the eutectic fibers $(\delta r / R \sim$ $0.004)$.

The only oxide fibers currently available commercially in quantities sufficient to fabricate composites are polycrystalline, with grain size $\sim 50-100 \mathrm{~nm}$ and diameter $\sim 12$ $\mu \mathrm{m} .{ }^{33,34}$ The surface roughness due to grain boundary grooving in as-fabricated fibers is typically very small $\left(<5 \mathrm{~nm}\right.$ for $3 \mathrm{M}$ Nextel $\left.720^{\mathrm{TM}}\right){ }^{35}$ However, the grooves would be expected to grow during processing of the matrix to depths up to about half of the grain size $(\sim 20-50 \mathrm{~nm})$. Although this roughness amplitude is smaller than that of the eutectic fibers, the mismatch strain is similar or larger $(\delta \mathrm{r} / \mathrm{R} \sim 0.003-0.005)$. Therefore, deformation of the coating might be expected if these fibers were to be embedded in a matrix with stiffness similar to that used in this study. However, in a composite with a porous matrix the response would be mitigated by the reduced constraint owing to the lower elastic stiffness of the matrix.

The maximum temperature capability of oxide composites is limited by the stability of currently available polycrystalline fibers. Directionally solidified eutectic fibers have the potential to provide large increases in use temperature through their greater microstructural stability, creep resistance, and strength retention. ${ }^{20.36}$ However, substantial development would be needed for economical production of fibers of smaller diameter suitable for composite reinforcements.

\subsection{Plastic deformation of $\mathrm{LaPO}_{4}$}


It is clear from Figs. 5-8 that sliding of rough interfaces over distances large compared with the roughness wavelength causes plastic deformation of the monazite coating. Plastic deformation of monazite by twinning and dislocations has also been observed after quasi-static contact with spherical indenters at room temperature. ${ }^{31.37}$ Such deformation can occur in any brittle material in the presence of sufficient hydrostatic pressure to suppress fracture. ${ }^{38-43}$ Since monazite, with a hardness of $5 \mathrm{GPa},{ }^{1}$ is much softer than alumina, zirconia, and mullite (hardnesses ranging from 10 to $40 \mathrm{GPa}$ ), ${ }^{44}$ sliding of these fibers is expected to deform the monazite without damaging the fibers.

Wear and abrasion of ceramics are known to cause intense plastic deformation, similar to that in heavily cold worked metals, with fine, heavily deformed wear debris as in Fig. 6$8 .^{43,45-48}$ The depth of the deformed zone is expected to be similar to the dimensions of the sliding asperities, consistent with the observations of Figs. 6-8. ( $\sim 500 \mathrm{~nm}$ depth of monazite deformation from sliding of $\mathrm{Al}_{2} \mathrm{O}_{3} / \mathrm{YAG}$ fiber with roughness amplitude $\sim 200$ $\mathrm{nm}$ and wavelength $\sim 1 \mu \mathrm{m})$. Mullite fibers, with larger roughness amplitude $(2.5 \mu \mathrm{m})$ and wavelength $(100 \mu \mathrm{m})$, deform the entire coating, rather than just a thin layer. Abrasive wear of interfaces in a composite can affect the fiber sliding resistance and thus the mechanical properties of the composite, particularly during fatigue. ${ }^{49}$

The presence of regions such as Fig. 6 that resemble recrystallized grains is unexpected. Recrystallization normally occurs only at sufficiently high temperatures and long times to allow dislocation climb. ${ }^{50}$ This would not be expected during room-temperature deformation of a refractory material such as $\mathrm{LaPO}_{4}$, and was not observed in indented monazite. ${ }^{31}$ In alumina, which has similar melting point, recovery and recrystallization 
of cold worked microstructures typically requires temperatures of at least $800^{\circ} \mathrm{C}^{45}$ and perhaps as high as $1200^{\circ} \mathrm{C}$, for formation of stable grain structures. ${ }^{51}$ This raises questions of whether friction caused local heating or whether another mechanism such as low temperature amorphization and recovery might be responsible for this microstructure. The latter mechanism has been observed in wear and abrasion of twophase metals. $^{48}$

\section{Local heating effects}

Several approaches, based on different assumptions about heat dissipation mechanisms, may be taken to estimate limits on increases in local temperatures during sliding. If deformation occurs quasi-statically and continuously, an upper (adiabatic) limit may be obtained by assuming that all work done by sliding asperities is dissipated as heat within the deformed zone ( $200 \mathrm{~nm}$ thickness in Fig. 6a). With further assumptions about the uniformity of heat generation and the ratio of cross-sectional areas of the asperities and the deformation zone, temperature rises between $800^{\circ} \mathrm{C}$ and $2000^{\circ} \mathrm{C}$ are obtained, depending on whether analysis is performed for individual asperities or for an average contact area (Appendix A). With the uncertainty in some parameters, these numbers could vary by a factor of 2 . Nevertheless, it is clear that large increases in temperature might be expected under adiabatic conditions.

However, adiabatic heating requires a sliding velocity sufficiently large that conduction of heat away from the deformation zone during sliding is negligible. Although the sliding velocity was not measured, we can calculate a very conservative upper bound. Comparison of the corresponding sliding time with an estimate of the time taken for heat 
dissipation by conduction (from standard transient heat flow solutions) suggests that the upper-bound sliding velocity is several orders of magnitude smaller than that required for adiabatic heating (Appendix A).

A similar conclusion is drawn from application of frictional sliding analyses, ${ }^{52-54}$ in which the assumption is made that work done by frictional forces is dissipated as heat at the interface between the sliding surfaces. Solutions for the interface temperature as a function of the sliding velocity are then obtained from analysis of heat flow into the materials on either side of the interface. Solutions are available at a macroscopic level (average) and at an asperity contact level for transient and steady-state conditions (Appendix A). In both cases, the calculated temperature increments for the upper-bound sliding velocity in these experiments are small $\left(\sim 0.5^{\circ} \mathrm{C}\right.$ for the asperity calculation and $\sim$ $5^{\circ} \mathrm{C}$ for the average calculation).

These calculations indicate that significant increases in temperature could not have occurred in these experiments if the assumptions of quasistatic, continuous deformation were valid. Two mechanisms could conceivably invalidate these assumptions. One is stick slip motion, causing local sliding velocities significantly larger than the average. ${ }^{55}$ The local velocity would need to exceed the maximum upper-bound average velocity by a factor of $\sim 100$ in order to approach adiabatic conditions (Appendix A). This is possible, since in theory local elastic unloading could cause local velocities approaching sonic values. However, experiments and geological observations find less heating during stick-slip than during stable sliding ${ }^{55}$ (reduction of normal stress by interface separation waves being suggested as a cause). 
The other mechanism is cataclastic flow ${ }^{30}$ followed by plastic deformation of the debris. Fine-grained $(50 \mathrm{~nm})$, angular, and porous monazite debris diagnostic of cataclastic flow was observed in some regions (Figs. 6-8). The prevalence of cold-worked and "recrystallized" deformation microstructures also varied from place to place, suggesting there was spatial and perhaps temporal variation in the intensity of deformation and/or local temperature rises during the push-out experiments. Local adiabatic heating could occur during cataclastic flow as a result of imperfect contact between the debris and the surroundings, leading to reduced heat conduction to the surroundings, or by local stickslip motion of the angular debris causing rapid impact of sharp particles. Fine-grained debris (fault gouge) is itself suspected to influence whether stick-slip or stable sliding occurs, with most observations pointing towards inhibition of stick-slip by fine-grained debris. $^{30}$ A progression from stick-slip to stable sliding as debris builds up during fiber push-out displacement is possible, with a consequent change in local temperature rises. Unfortunately, it is not straightforward to assess any of these effects quantitatively.

\section{Annealing of radiation damage}

Monazites are extremely resistant to amorphization by radiation damage, and are thus ideal hosts for containment of actinide or transuranic elements. ${ }^{56,57}$ Natural monazites with large concentrations of radioactive thorium and uranium are always found as crystals rather than as an amorphous or metamict mineral. Studies using synthetic monazite crystals show that this is due to the ability of monazite to recover readily from displacive damage events at near-ambient temperatures. ${ }^{58,59}$ 
In a recent study, ${ }^{60}$ radiation damage in $\mathrm{LaPO}_{4}$ and several related $\mathrm{ABO}_{4}$-type phosphates and silicates was monitored as a function of temperature in situ by TEM. Fundamental differences in the amorphization and recrystallization kinetics between the orthophosphates and silicates were observed. The critical temperature above which amorphization could not be induced (i.e., recrystallization processes were faster than damage accumulation) was only $35^{\circ} \mathrm{C}$ for $\mathrm{LaPO}_{4}$, but more that $700^{\circ} \mathrm{C}$ for zircon. This difference was tentatively attributed to the higher stability of isolated $\mathrm{PO}_{4}$ tetrahedra than isolated $\mathrm{SiO}_{4}$ units, with less bond breaking being required to crystallize the amorphous structure.

Similar arguments might apply for recrystallization after intense mechanical deformation. However, recrystallization of a material with high density of dislocations requires lattice diffusion for dislocation climb. ${ }^{50}$ Crystallization after amorphization by radiation damage does not involve such diffusion. Nevertheless, the resistance of monazite to amorphization hints that solid-state processes in monazite are faster than those in many other ceramics, such as alumina and zircon, at similar homologous temperatures. Whether recrystallization of intensely cold-worked monazite might occur near room temperature should be determined by independent measurements of nucleation, recrystallization, grain growth, and diffusion.

\section{SUMMARY AND CONCLUSIONS}

La-monazite is compatible with mullite, $\mathrm{YAG}, \mathrm{ZrO}_{2}$ and $\mathrm{Al}_{2} \mathrm{O}_{3}$. The interfaces between La-monazite and these materials are sufficiently weak to allow debonding when a crack approaches the interface from within the monazite. This occurs even in the presence of 
substantial residual compressive stresses normal to the interface, as in the case of the mullite fiber in an alumina matrix.

All of the monazite-coated fibers (single crystal mullite, alumina, eutectic $\mathrm{Al}_{2} \mathrm{O}_{3} / \mathrm{YAG}$ and eutectic $\mathrm{Al}_{2} \mathrm{O}_{3} / \mathrm{ZrO}_{2}$ fibers) underwent sliding in single fiber push-out experiments.

Sliding occurred along a single interfacial debond when the displacements were small and/or the fiber surfaces were relatively smooth. At larger displacements the eutectic fibers, which had rougher interfaces than the single crystal mullite and alumina fibers, caused extensive damage in the $\mathrm{LaPO}_{4}$ coating adjacent to the fiber. The mullite fibers, which had smooth surfaces but large oscillations in diameter, caused deformation through the entire thickness of the coating in regions of large misfit strain. Damage mechanisms included fracture, dislocation plasticity, and occasional twinning. The fibers were undamaged, as might be expected given their higher hardnessess. The relative softness of La-monazite, resulting from its ability to deform plastically at low temperatures, may be critical for its use as a composite interface.

TEM observations showed evidence suggesting that recrystallization may have occurred within the intensely deformed monazite. Several analyses indicated that significant frictional heating during sliding was unlikely unless stick-slip motion caused large increases in local sliding velocities. The absence of significant heating would imply that recrystallization of heavily deformed monazite is possible at room temperature, an unusual behavior for such a refractory material. However, such behavior might be consistent with observations of recrystallization from radiation damage in La-monazite at much lower temperatures than in other minerals. 


\section{ACKNOWLEDGEMENTS}

Funding for this work at Rockwell was provided by the U.S. Air Force Office of Scientific Research under contract F49620-96-C-0026.

Work at NASA on development of new directionally solidified fibers were supported by a U.S. Air Force Office of Scientific Research under contract F49620-00-1-0048 and National Aeronautics and Space Administration contract number NCC3-372. 


\section{REFERENCES}

1. P. E. D. Morgan and D. B. Marshall, "Ceramic Composites of Monazite and Alumina," J Am Ceram Soc, 78 1553-63 (1995).

2. P. E. D. Morgan, D. B. Marshall and R. M. Housley, "High Temperature Stability of Monazite-Alumina Composites," J. Mat. Sci. Eng., A195 215 - 222 (1995).

3. D. B. Marshall, P. E. D. Morgan, R. M. Housley and J. T. Cheung, "High temperature Stability of the $\mathrm{Al}_{2} \mathrm{O}_{3}-\mathrm{LaPO}_{4}$ System," J. Am. Ceram. Soc., 81[4] 951-56 (1998).

4. D. B. Marshall, J. B. Davis, P. E. D. Morgan and J. R. Porter, "Interface Materials for Damage-Tolerant Oxide Composites," Key Engineering Materials, 127-131 27-36 (1997).

5. J. B. Davis, D. B. Marshall and P. E. D. Morgan, "Oxide Composites of $\mathrm{Al}_{2} \mathrm{O}_{3}$ and $\mathrm{LaPO}_{4}$,"J. European Ceram. Soc., 19 2421-2426 (1999).

6. J. B. Davis, D. B. Marshall and P. E. D. Morgan, "Monazite Containing Oxide-Oxide Composites," J. Eur. Ceram. Soc., 20[5] 583 - 587 (2000).

7. K. A. Keller, T.-I. Mah, E. E. Boakye and T. A. Parthasarathy, "Gel-Casting and Reaction Bonding of Oxide-Oxide Minicomposites with Monazite Interphase," Ceramic Engineering and Science Proceedings, 21[4] 525-534 (2000).

8. T. A. Parthasarathy, E. Boakeye, M. K. Cinibulk and M. D. Perry, "Fabrication and Testing of Oxide/Oxide Microcomposites with Monazite and Hibonite as Interlayers," $J$. Amer. Ceram. Soc., 82[12] 3575-3583 (1999).

9. S. M. Johnson, Y. Blum, C. Kanazawa, H.-J. Wu, J. R. Porter, P. E. D. Morgan, D. B. Marshall and D. Wilson, "Processing and Properties of an Oxide/Oxide Composite," Key Engineering Materials, 127-131 231-38 (1997).

10. S. M. Johnson, Y. Blum and C. H. Kanazawa, "Development and Properties of an Oxide Fiber-Oxide Matrix Composite," Key. Eng. Mat., 164-165 85-90 (1999).

11. K. A. Keller, T. Mah, T. A. Parthasarathy, E. E. Boakye and M. Cinibulk, "Evaluation of all-oxide composites based on coated Nextel 610 and 650 fibers," Ceramic Engineering and Science Proceedings, in press (2001).

12. Y. Hikichi and T. Nomura, "Melting Temperatures of Monazite and Xenotime," $J$. Am. Cer. Soc., 70[10] C252-C253 (1987). 
13. D. B. Marshall, P. E. D. Morgan and R. M. Housley, "Debonding in Multilayered Composites of Zirconia and $\mathrm{LaPO}_{4}$," J. Am. Ceram. Soc., 80[7] 1677-83 (1997).

14. D.-H. Kuo and W. M. Kriven, "Characterization of Yttrium Phosphate and a Yttrium Phosphate/Yttrium Aluminate Laminate," J. Am. Ceram. Soc., 78[11] 3121-3124 (1995).

15. M. G. Cain, R. L. Cain, A. Tye, P. Rian, M. H. Lewis and J. Gent, "Structure and Stability of Synthetic Interphases in CMCs," Key Engineering Materials, 127-131 37-49 (1997).

16. D.-H. Kuo, W. M. Kriven and T. J. Mackin, "Control of interfacial Properties Through Fiber Coatings: Monazite Coatings in Oxide-Oxide Composites," J. Am. Ceram. Soc., 80[12] 2987-96 (1997).

17. R. J. Kerans and T. A. Parthasarathy, "Debond Crack Roughness, Interface Properties and Fiber Coating Design in Ceramic Composites," Key Engineering Materials, 127-131 51-62 (1977).

18. A. Sayir, "Directional Solidification of Eutectic Ceramics"; pp 197-211 in Computer Aided Design of High Temperature Materials. Eds A. Pechenik, R. Kalia and P. Vashishta. Oxford, Oxford University Press, 1999.

19. A. Sayir and S. C. Farmer, "Directionally Solidified Mullite Fibers," Mat. Res. Soc. Proc., 365 11-21 (1995).

20. A. Sayir and S. C. Farmer, "The Effect of the Microstructure on Mechanical Properties of Directionally Solidified Al2O3/ZrO2(Y2O3) Eutectic," Acta Mater., 48[1819] 4691-97 (2000).

21. A. Sayir and L. E. Matson, "Growth and Characterization of Directionally Solidified Al2O3/Y3Al5O12 (YAG) Eutectic Fibers," Proc. of the 2nd Ann. HITEMP Rev, 83 1-14 (1991).

22. T. A. Hahn, "Thermal stress relaxation due to plastic flow in the fiber coating of a continuous fiber reinforced composite," Journal of Composite Materials, 27[16] 15451577 (1993).

23. W. M. Kriven, J. W. Palko, S. Sinogeikin, J. D. Bass, A. Sayir, G. Brunauer, H. Boysen, F. Frey and J. Schneider, "High Temperature Single Crystal Properties of Mullite," J. Europ. Ceram. Soc., 192529 - 2541 (1999).

24. Y. S. Touloukian, R. K. Kirby, R. E. Taylor and T. Y. R. Lee, Thermal Expansion Non Metallic Solids. New York, Plenum (1977). 
25. S. Geller, G. P. Espinosa and P. B. Crandall, "Thermal Expansion of Yttrium and Gadolinium Iron, Galluim and Aluminum Garnets," J. Appl. Crystallography, 2 86-88 (1969).

26. R. S. Hay, J. R. Welch and M. K. Cinibulk, "TEM Specimen Preparation and Characterization of Ceramic Coatings on Fiber Tows," Thin Solid Films,, 308-309 389392 (1997).

27. M.-Y. He and J. W. Hutchinson, "Crack Deflection at an Interface Between Dissimilar Materials," Int. J. Solids Struct., 25 1053-1067 (1989).

28. D. B. Marshall, J. B. Davis, P. E. D. Morgan, J. R. Waldrop and J. P. Porter, "Properties of La-Monazite as an Interphase in Oxide Composites," Zeitschrift fur Metallkunde, 90[12] 1048-1052 (1999).

29. D. B. Marshall, J. R. Waldrop and P. E. D. Morgan, "Thermal Grooving at the Interface Between Alumina and Monazite," Acta Mat., 48 4471-4474 (2000).

30. M. S. Paterson, pp 254 in Experimental Rock Deformation - The Brittle Field. Heidelberg, NY, Springer-Verlag, Berlin, 1978.

31. R. S. Hay, "Monazite and Scheelite Deformation Mechanisms," Ceramic Engineering and Science Proceedings, 21[4] 203-228 (2000).

32. M.-Y. He, A. G. Evans and J. W. Hutchinson, "Crack Deflection at an Interface Between Dissimilar Elastic Materials: Role of Residual Stresses," Int. J. Solids Structures, 31[24] 3443-3455 (1994).

33. R. S. Hay, E. Boakeye, M. D. Petry, Y. Berta, K. Von Lehmden and J. Welch, "Grain Growth and Tensile Strength of 3-M Nextel 720TM after Thermal Exposure," Ceramic Engineering and Science Proceedings, 20[3] 165-172 (1999).

34. D. M. Wilson and L. R. Visser, "Nextel 650 Ceramic Oxide Fiber: New Aluminabased Fiber for High Temperature Composite Reinforcement," Ceramic Engineering and Science Proceedings, 21[4] 363-373 (2000).

35. A. Romoscanu, "Topography Characterization of Alumina-Mullite Fibers Using Atomic Force Microscopy and Relationship to Mechanical Properties," Masters thesis, University of Pennsylvania (1998).

36. L. E. Matson and N. Hecht, "Microstructural Stability and Mechanical Properties of Directionally Solidified Alumina/YAG Eutectic Monofilaments,", J. European Ceram. Soc., 19 2487-2503 (1999).

37. J. B. Davis, D. B. Marshall, P. E. D. Morgan and R. M. Housley, "Machinable Ceramics Containing Rare-Earth Phosphates," J. Am. Ceram. Soc., 81[8] 2169-75 (1998). 
38. B. J. Hockey, "Plastic Deformation of Aluminum Oxide by Indentation and Abrasion," J. Am. Ceram. Soc., 54[5] 223-31 (1971).

39. A. H. Heuer, "Deformation Twinning in Corundum," Philos. Mag. A, 13[122] 37993 (1966).

40. R. M. Cannon, "Structure and Properties of MgO and Al2O3"; pp 818-38 in Advances in Ceramics. Ed. W. D. Kingery. Columbus, Ohio, The American Ceramic Society. 10, 1984.

41. H. M. Chan and B. R. Lawn, "Indentation Deformation and Fracture of Sapphire," $J$. Am. Ceram. Soc., 71[1] 29-35 (1988).

42. K. P. D. Lagerlof, A. H. Heuer, J. Castaing, J. P. Riviere and T. E. Mitchell, "Slip and Twinning in Sapphire (a-Al2O3)," J. Am. Ceram. Soc., 77[2] 385-97 (1994).

43. S. B. Toh and R. McPherson, "Plastic Deformation During the Abrasive Wear of Ceramics"; pp 723-732 in Deformation of Ceramic Materials. Eds R. E. Tressler and R. C. Bradt. New York and London, Plenum Press. II, 1984.

44. I. J. McColm, pp 324 Ceramic Hardness. New York, Plenum Press, 1990.

45. I. A. Cutter and R. McPherson, "Plastic Deformation of Alumina During Abrasion," J. Am. Ceram. Soc., 56266 (1973).

46. S.-J. Cho, H. Moon, B. J. Hockey and S. M. Hsu, "The Transition from Mild to Severe Wear in Alumina During Sliding," Acta metall. mater., 40[1] 185-192 (1992).

47. B. J. Inkson, "Dislocations and Twinning Activated by the Abrasion of Alumina," Acta mater., 48 1883-1895 (2000).

48. D. Kuhlmann-Wilsdorf, "What Role for Contact Spots and Dislocations in Friction and Wear," Wear, 200 8-29 (1996).

49. H. Kakisawa and Y. Kagawa, "Effect of Abrasive Wear on Interfacial Shear Sliding Resistance in SiC Fiber-Reinforced Al2O3 Matrix Composite," Ceram. Eng. Sci. Proc., 18[3] 757-762 (1997).

50. F. J. Humphreys and M. Hatherly, p497 in Recrystallization and Related Annealing Phenomena, Pergamon, 1st ed., 1996.

51. B. J. Hockey, "Observations by Transmission Electron Microscopy of the Subsurface Damage Produced in Aluminum Oxide by Mechanical Polishing and Abrasion," Proc. Brit. Ceram. Soc., 20 95-115 (1972). 
52. F. P. Bowden and D. Tabor, Friction and Lubrication of Solids, Parts I and II. Oxford, U.K., Clarendon Press (1964).

53. J. C. Jaeger, Jour. \& Proc. Roy. Soc. NSW, 76203 (1942).

54. M. F. Ashby, J. Abulawi and H. S. Kong, "Temperature Maps For Frictional Heating in Dry Sliding," Tribology Transactions, 34[4] 577-587 (1991).

55. S. Brown, "Frictional Heating on Faults: Stable Sliding versus Stick-Slip," $J$.

Geophys. Res., 103[B4] 7413-7420 (1998).

56. L. A. Boatner and B. C. Sales, "Monazite"; in Radioactive Waste Forms for the Future. Eds W. Lutze and R. C. Ewing. New York, North-Holland. Chapter 8, 1988.

57. A. Meldrum, L. A. Boatner and R. C. Ewing, "Electron-Irradiation-Induced Nucleation and Growth in Amorphous LaPO4, ScPO4, and Zircon," J. mater. Res., 12[7] 1816-1827 (1997).

58. F. G. Karioris, K. A. Gowda and L. Cartz, "Heavy Ion Bombardment of Monoclinic ThSiO4, ThO2 and Monazite," Radiation Effects Letters, 58 1-3 (1981).

59. T. C. Ehlert, K.A. Gowda, F. G. Karioris and L. Cartz, "Differential Scanning Calorimetry of Heavy Ion Bombarded Synthetic Monazite," Radiation Effects, 70 173181 (1983).

60. A. Meldrum, L. A. Boatner and R. C. Ewing, "A Comparison of Radiation Effects in Crystalline ABO4-type Phosphates and Silicates," Mineralogical Magazine, 64[2] 185194 (2000).

61. Y. Hikichi, T. Nomura, Y.Tanimura and S. Suzuki, "Sintering and Properties of Monazite-type $\mathrm{CePO}_{4}$," J. Am. Ceram. Soc., 73[12] 3594-3596 (1990).

62. F. P. Incropera and D. P. DeWitt, INTRODUCTION TO HEAT TRANSFER. New York, Wiley, (1996).

63. Y. S. Touloukian, R. W. Powell, C. Y. Ho and P. G. Klemens, Thermal Conductivity - Non Metallic Solids. New York, Plenum (1970). 


\section{Appendix A: Estimates of Heating due to fiber sliding}

Several approaches, based on different assumptions about dissipation mechanisms, may be taken to estimate limits on local temperature rises during fiber sliding. Some results from these analyses are summarized below

\section{Adiabatic sliding}

If we assume that the work done by sliding friction is dissipated entirely by uniform adiabatic heating in a zone of deformed monazite adjacent to the plane of sliding, the temperature rise is:

$$
\Delta \mathrm{T}=\tau_{\mathrm{s}} \delta /\left(\rho \mathrm{c}_{\mathrm{p}} \mathrm{h}\right)
$$

where $\tau_{\mathrm{s}}$ is the sliding friction stress, $\delta$ is the sliding displacement, $\mathrm{h}$ is the thickness of the deformation zone, and $\rho$ and $c_{p}$ are the density and specific heat of the monazite. For the sliding experiment corresponding to Fig. 6 , the measured parameters are: $\tau_{\mathrm{s}} \sim 200$ $\mathrm{MPa}, \delta=5 \mu \mathrm{m}$ and $\mathrm{h} \sim 0.2 \mu \mathrm{m}$. With $\rho=5 \mathrm{~g} / \mathrm{cm}^{3}$ and $\mathrm{c}_{\mathrm{p}}=500 \mathrm{~J} / \mathrm{kg} . \mathrm{K}$, ${ }^{61}$ Eq. (A1) gives $\Delta \mathrm{T}=2000^{\circ} \mathrm{C}$.

An alternative estimate based on incremental sliding of individual asperities, as depicted in Fig A1, gives the temperature rise:

$$
\Delta \mathrm{T}=\mathrm{HA} \mathrm{A}_{\mathrm{a}} /\left(\rho \mathrm{c}_{\mathrm{p}} \mathrm{A}_{\mathrm{b}}\right),
$$

where $\mathrm{H}$ is the hardness of the monazite, $\mathrm{A}_{\mathrm{a}}$ is the cross-sectional area of the asperity and $\mathrm{A}_{\mathrm{b}}$ is the cross-sectional area of the plastic deformation zone created by the asperity as it slides (the sliding force acting on the asperity being set equal to $\mathrm{H} \mathrm{A}_{\mathrm{a}}$ ). If we take $\mathrm{H}$ as the room temperature hardness of monazite $(\sim 5 \mathrm{GPa})^{1}$ and $\mathrm{A}_{b} / \mathrm{A}_{\mathrm{a}} \sim 2$ (from Fig. 6), Eq. (A2) gives $\Delta \mathrm{T}=1000^{\circ} \mathrm{C}$.

Both of these estimates are subject to considerable uncertainty (a factor of $\sim 2$ ) associated with the parameters $h$ and $A_{a} / A_{b}$ as well as the assumption of uniform heating within the zone. Nevertheless, they indicate that large local temperature rises could occur if the sliding velocity is sufficiently large to cause adiabatic conditions.

\section{Estimated sliding velocity and transient heating effects}

The time in transient heat conduction problems always appears normalized by the characteristic time, $\tau:^{62}$

$$
\tau=\rho c_{p} d^{2} / k
$$

where $\mathrm{k}$ is the thermal conductivity and $\mathrm{d}$ is a characteristic diffusion distance. In the fiber sliding problem, $\mathrm{d}$ is the depth of the deformation zone and the conditions are close 
to adiabatic only if the time, $t_{\mathrm{h}}$, taken to heat the deformation zone is small compared with $\tau$. If we assume that heat is conducted only into the monazite $(\mathrm{k} \sim 2 \mathrm{~W} / \mathrm{m} . \mathrm{K}),{ }^{61} \tau$ is $\sim 10^{-7} \mathrm{~s}$ for a zone of depth $\sim 0.2 \mu \mathrm{m}$. The time $t_{\mathrm{h}}$ is given by $t_{\mathrm{h}}=\delta / \mathrm{v}$, where $\delta$ is the sliding distance and $\mathrm{v}$ is the sliding velocity.

Although the sliding velocity was not measured in the experiments described in section 2 , a very conservative upper bound may be estimated. The experiments involved loading the indenter on the end of the fiber using a fixed weight lowered slowly (velocity less than $10^{-4} \mathrm{~m} / \mathrm{s}$ ) by a viscous dash-pot. When the interface debonded, the sliding fiber accelerated unstably until the indenter contacted the matrix. The magnitude of the acceleration was determined by the resultant force on the fiber (the difference between the combined weight of the loading mass, indenter, and fiber and the opposing forces due to sliding friction and the dash-pot). An upper bound for this acceleration, corresponding to zero resistance from sliding and the dash-pot, is the gravitational acceleration, g. This acceleration acting over the measured sliding displacement $(\sim 5$ $\mu \mathrm{m}$ ) would result in a maximum velocity of $10^{-2} \mathrm{~m} / \mathrm{s}$. A less conservative overestimate obtained by the assuming that the sliding friction remains constant during the test gives a value smaller by a factor of 15 .

With the upper-bound velocity of $10^{-2} \mathrm{~m} / \mathrm{s}$ and the sliding distance $\delta=5 \mu \mathrm{m}$ for the average analysis of Eq. (A1), the lower bound estimate for the heat input time is $t_{h} \sim 5 \mathrm{x}$ $10^{-4} \mathrm{~s}$. This is more than 3 orders of magnitude larger than the value of $\tau$ estimated above, indicating that adiabatic conditions are not approached. For the asperity sliding analysis (Eq. (A2)), the relevant sliding distance is smaller (equal to the dimensions of the asperity, $\sim 0.5 \mu \mathrm{m}$ ) giving a smaller heat input time, although still far from adiabatic conditions $\left(\mathrm{t}_{\mathrm{h}} / \tau \sim 10^{2}\right)$.

It is worth noting the role of asperity size in the above analysis. Since both $d$ in Eq. (A3) and the sliding distance $\delta$ that determines the sliding time $\left(\mathrm{t}_{\mathrm{h}}\right)$ scale with the asperity size, the ratio $t_{h} / \tau$ increases with decreasing asperity size. Therefore, if the damage observed in Fig. 6 was caused by sequential sliding of asperities of various sizes, the conditions for the smaller asperities would have been further from adiabatic. Given the conservative nature of these estimates it appears unlikely that large temperature increases could have occurred in these experiments if sliding occurred uniformly.

\section{Frictional sliding analyses}

In the literature on frictional sliding the assumption is made that work done by frictional forces is dissipated as heat at the interface between the sliding surfaces. ${ }^{52-54}$ Solutions for the interface temperature as a function of the sliding velocity are obtained from analysis of heat flow into the materials either side of the interface. Solutions are available at a macroscopic level (average) and at an asperity contact level for transient and steady state conditions. These solutions can be written in the general form ${ }^{54}$

$$
\Delta \mathrm{T}=\left(\mathrm{F}_{\mathrm{s}} \mathrm{v} / \mathrm{A}\right)\left(\mathrm{k}_{1} / \ell_{1}+\mathrm{k}_{2} / \ell_{2}\right)^{-1}
$$


where $\Delta \mathrm{T}$ is the difference between the interface temperature and the remote temperature, $\mathrm{F}_{\mathrm{s}}$ is the sliding force, $\mathrm{v}$ the velocity, $\mathrm{A}$ the contact area, $\mathrm{k}_{1}$ and $\mathrm{k}_{2}$ are the thermal conductivities of materials 1 and 2 either side of the interface, and $\ell_{1}$ and $\ell_{2}$ are functions of the contact geometry, thermal diffusivities $(\alpha)$ and the time over which the heat is applied. A limitation of these models is that $\Delta \mathrm{T}$ increases without limit as the sliding velocity increases (i.e. as adiabatic conditions are approached), a consequence of the assumption that the heat is dissipated at the interface rather than in a deformation zone of finite volume.

For the analysis of sliding asperities, a convenient solution for $\ell_{1}$ and $\ell_{2}$ is that of a Gaussian heat source applied for a time t over a circular contact area of radius $\mathrm{r}_{0} .^{54}$

$$
\ell=\mathrm{r}_{\mathrm{o}} \pi^{-1 / 2} \tan ^{-1}\left(4 \mathrm{t} \alpha / \mathrm{r}_{\mathrm{o}}^{2}\right)^{1 / 2} .
$$

An upper bound for the sliding force on an asperity is given by taking the contact pressure equal to the hardness of the monazite and a friction coefficient of unity, so that $\mathrm{F}_{\mathrm{s}} / \mathrm{A}=\mathrm{H}$. For asperity contact times between the limits $\sim \mathrm{r}_{\mathrm{o}} / \mathrm{v}$ and $\delta / \mathrm{v}$, the temperature rise estimated from Eq. (A4) for a $\mathrm{Al}_{2} \mathrm{O}_{3} / \mathrm{YAG}$ asperity with $\mathrm{r}_{0}=0.2 \mu \mathrm{m}, \alpha \sim 0.05 \mathrm{~cm}^{2} / \mathrm{s}$, $\mathrm{k} \sim 20 \mathrm{~W} / \mathrm{m} . \mathrm{K},{ }^{63}$ and other parameters as defined above is $\sim 0.5^{\circ} \mathrm{C}$. An alternative analysis based on the measured sliding force and uniform contact gave $\Delta \mathrm{T} \sim 5^{\circ} \mathrm{C}$. 


\section{FIGURE CAPTIONS}

1. SEM micrographs of fiber surfaces: (a) $\mathrm{Al}_{2} \mathrm{O}_{3} / \mathrm{ZrO}_{2}$ eutectic fiber, (b) $\mathrm{Al}_{2} \mathrm{O}_{3} / \mathrm{YAG}$ eutectic fiber, and (c) mullite single crystal fiber.

2. SEM micrographs showing interactions of indentation cracks with $\mathrm{Al}_{2} \mathrm{O}_{3} / \mathrm{YAG}$ eutectic fibers: (a) uncoated fiber in alumina matrix (indentation located below region shown); (b) fiber coated with $\mathrm{LaPO}_{4}$ (indentation located out of field of view, as indicated in (d)); (c) same fiber as in (b) but showing region further along the debonded interface (arrows indicate magnitude of sliding displacement across debond crack); (d) schematic showing locations of (b) and (c).

3. SEM micrographs showing interactions of indentation cracks with $\mathrm{Al}_{2} \mathrm{O}_{3} / \mathrm{ZrO}_{2}$ eutectic fibers: (a) uncoated fiber in alumina matrix (indentation located below region shown); (b) fiber coated with $\mathrm{LaPO}_{4}$ (indentation located at top of field of view).

4. SEM micrographs showing interaction of indentation crack with single-crystal mullite fiber (coated with $\mathrm{LaPO}_{4}$, in alumina matrix): (a) intersection of indentation crack with interface and debonding (indentation located above region shown); (b) same fiber as in (a) but showing region further to the right along the debonded interface (arrows indicate magnitude of sliding displacement across debond crack).

5. SEM micrographs showing $\mathrm{Al}_{2} \mathrm{O}_{3} / \mathrm{ZrO}_{2}$ eutectic fiber after push-out: (a) bottom of push-out specimen (monazite-coated eutectic fiber, polycrystalline $\mathrm{Al}_{2} \mathrm{O}_{3}$ matrix); (b) monazite layer remaining attached to fiber, showing deformation due to sliding. 
6 TEM micrographs from cross-section of monazite-coated $\mathrm{Al}_{2} \mathrm{O}_{3} / \mathrm{YAG}$ fiber after pushout. Monazite recrystallization along the debond crack is evident at high-magnification. Heavily deformed monazite debris is evident between asperities on the fiber surface (intermediate magnification).

7 TEM micrograph of monazite smeared onto $\mathrm{Al}_{2} \mathrm{O}_{3} / Y A G$ fiber surface. The layer adjacent to the fiber is recrystallized on a $\sim 10-20 \mathrm{~nm}$ scale. The layer over it has more porous, coarse-grained angular particles diagnostic of cataclastic flow.

8 Intense plastic deformation and fine- scale microcracking in coating on $\mathrm{Al}_{2} \mathrm{O}_{3} / \mathrm{YAG}$ fiber. A heavily deformed ball of monazite $(\sim 100 \mathrm{~nm}$ diameter) is in the debond crack in the lower right-hand corner of the high-magnification inset.

9. Schematic of fiber sliding for monazite-coated mullite fiber.

10 Monazite coating on mullite fiber: region that was thought to have experienced tension during fiber sliding (as in Region A, Fig. 9). Monazite next to the fiber is mostly undamaged, but entire coating is cracked. Compression increases towards the right side of the micrograph.

11 Monazite coating on mullite fiber: region that was thought to have experienced compression during fiber sliding (as in Region B, Fig. 9). The coating is heavily deformed through the entire thickness, although with grain-to-grain variation. Large cracks tend to run NW - SE.

A1. Schematic showing asperity sliding and associated deformation zone. 

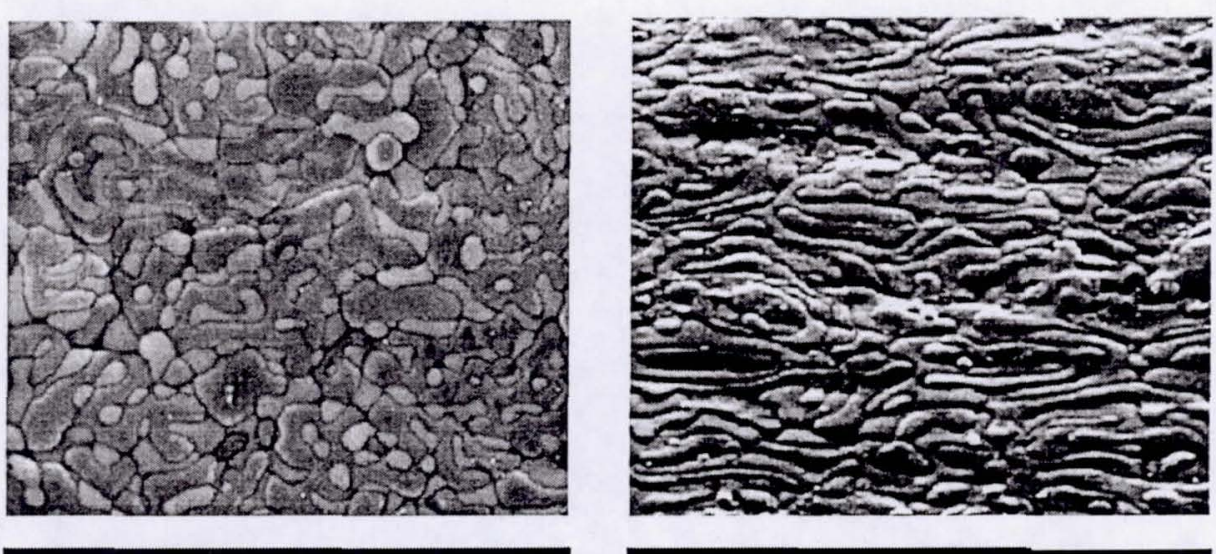

$\mathrm{Al}_{2} \mathrm{O}_{3} / \mathrm{ZrO}_{2}$ (eutectic)

\section{$\mathrm{YAG} / \mathrm{Al}_{2} \mathrm{O}_{3}$ (éutectic)}

(a)

(b)

\section{Mullite (single crystal)}

(c)

Fig. 1. Scanning electron micrographs of fiber surfaces: (a) $\mathrm{Al}_{2} \mathrm{O}_{3} / \mathrm{ZrO}_{2}$ eutectic fiber, (b) $\mathrm{Al}_{2} \mathrm{O}_{3} / \mathrm{YAG}$ eutectic fiber, and (c) mullite single crystal fiber. 


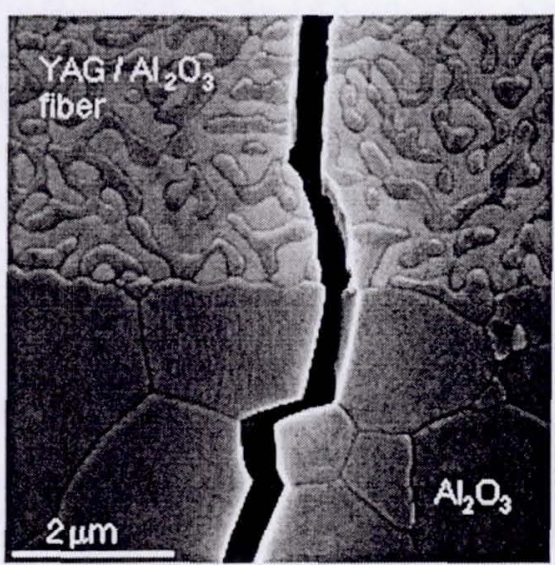

(a)

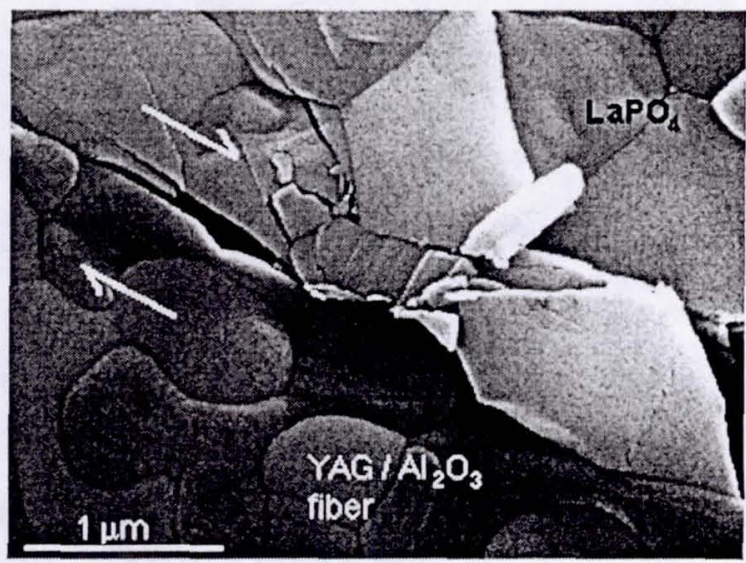

(c)

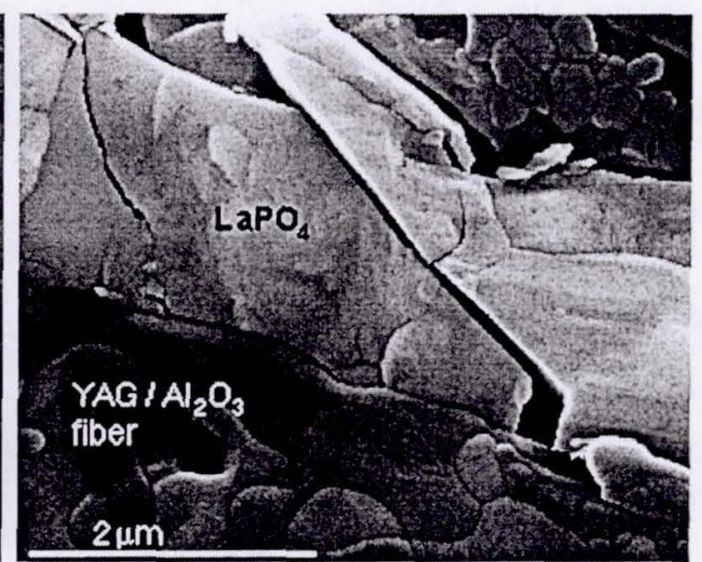

(b)

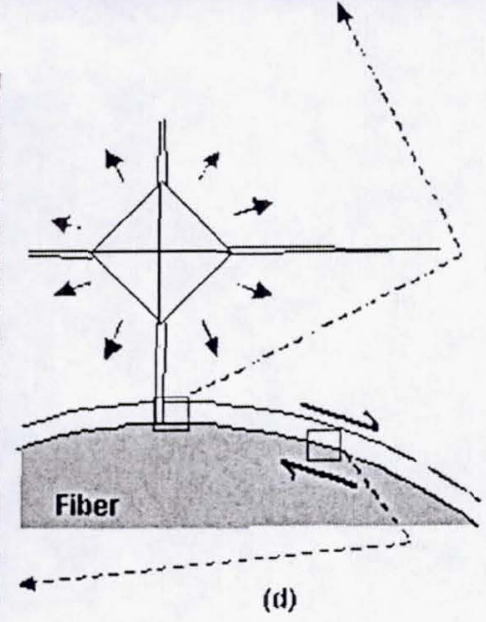

Fig. 2. SEM micrographs showing interaction of indentation cracks with $\mathrm{YAG} / \mathrm{Al}_{2} \mathrm{O}_{3}$ eutectic fibers: (a) uncoated fiber in alumina matrix (indentation located below the region shown); (b) fiber coated with $\mathrm{LaPO}_{4}$ (indentation located out of field of view, as indicated in (d)); (c) same fiber as in (b) but showing region further along the debonded interface (arrows indicate magnitude of sliding displacement across debond crack); (d) schematic showing locations of (b) and (c). 

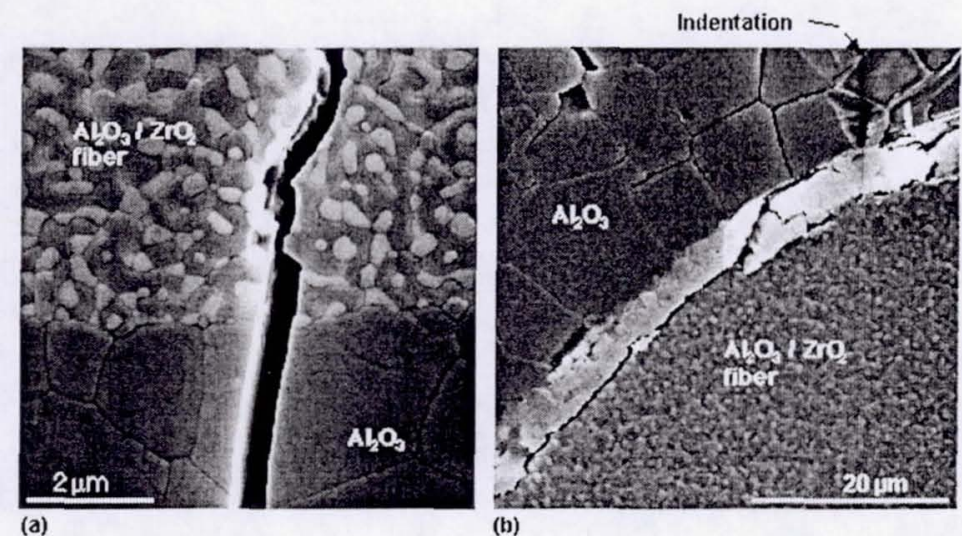

Fig.3. SEM micrographs showing interactions of indentation cracks with $\mathrm{Al}_{2} \mathrm{O}_{3} / \mathrm{ZrO}_{2}$ eutectic fibers: (a) uncoated fiber in alumina matrix (indentation located below region shown); (b) fiber coated with $\mathrm{LaPO}_{4}$ (indentation located at top of field of view).

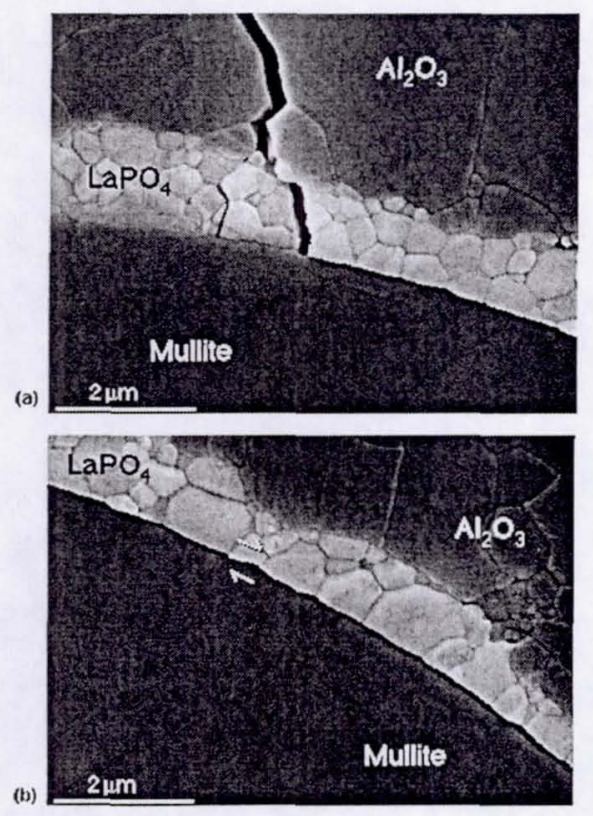

Fig. 4. SEM micrographs showing interaction of indentation crack with single-crystal mullite fiber (coated with $\mathrm{LaPO}_{4}$, in alumina matrix): (a) intersection of indentation crack with interface and debonding (indentation located above region shown); (b) same fiber as in (a) but showing region further to the right along the debonded interface (arrows indicate magnitude of sliding displacement across debond crack). 


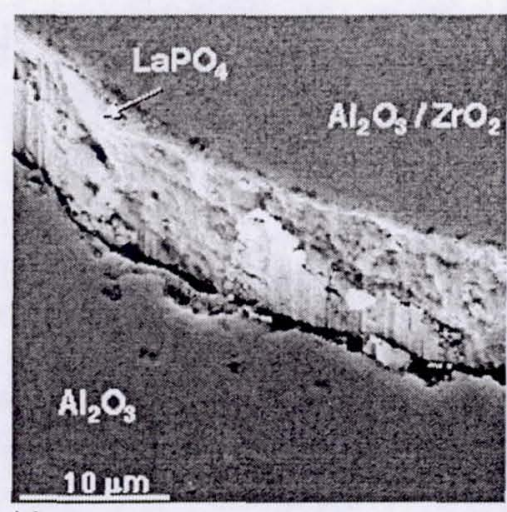

(a)

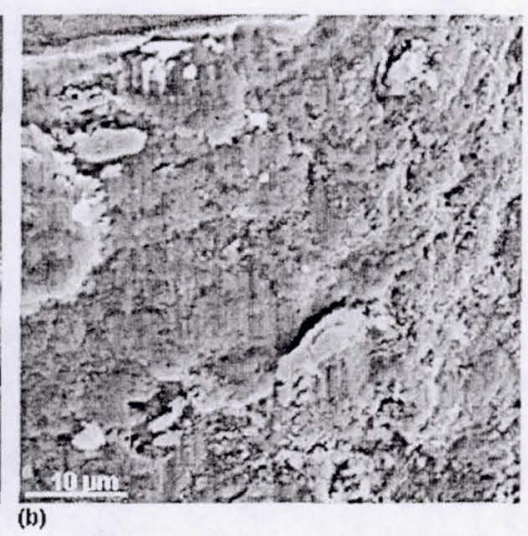

Fig. 5. SEM micrographs showing $\mathrm{Al}_{2} \mathrm{O}_{3} / \mathrm{ZrO}_{2}$ eutectic fiber after push-out: (a) bottom of push-out specimen (monazite-coated eutectic fiber, polycrystalline $\mathrm{Al}_{2} \mathrm{O}_{3}$ matrix); (b) monazite layer remaining attached to fiber, showing deformation due to sliding.

1. Schematic showing asperity sliding and associated deformation zone. 


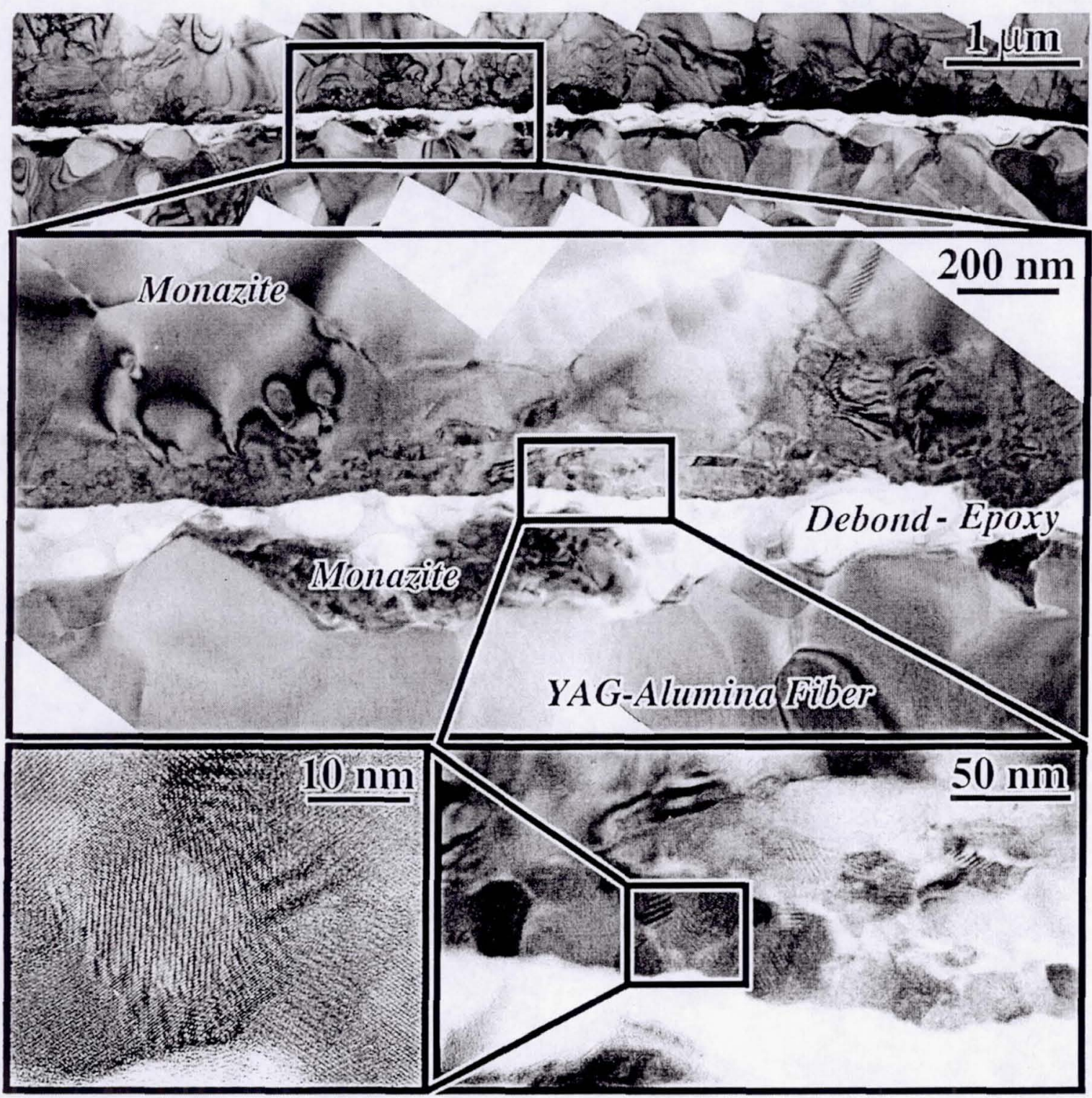

Fig. 6. TEM micrographs from cross-section of monazite-coated $\mathrm{Al}_{2} \mathrm{O}_{3} / \mathrm{YAG}$ fiber after push-out. Monazite recrystallization along the debond crack is evident at highmagnification. Heavily deformed monazite debris is evident between asperities on the fiber surface (intermediate magnification). 

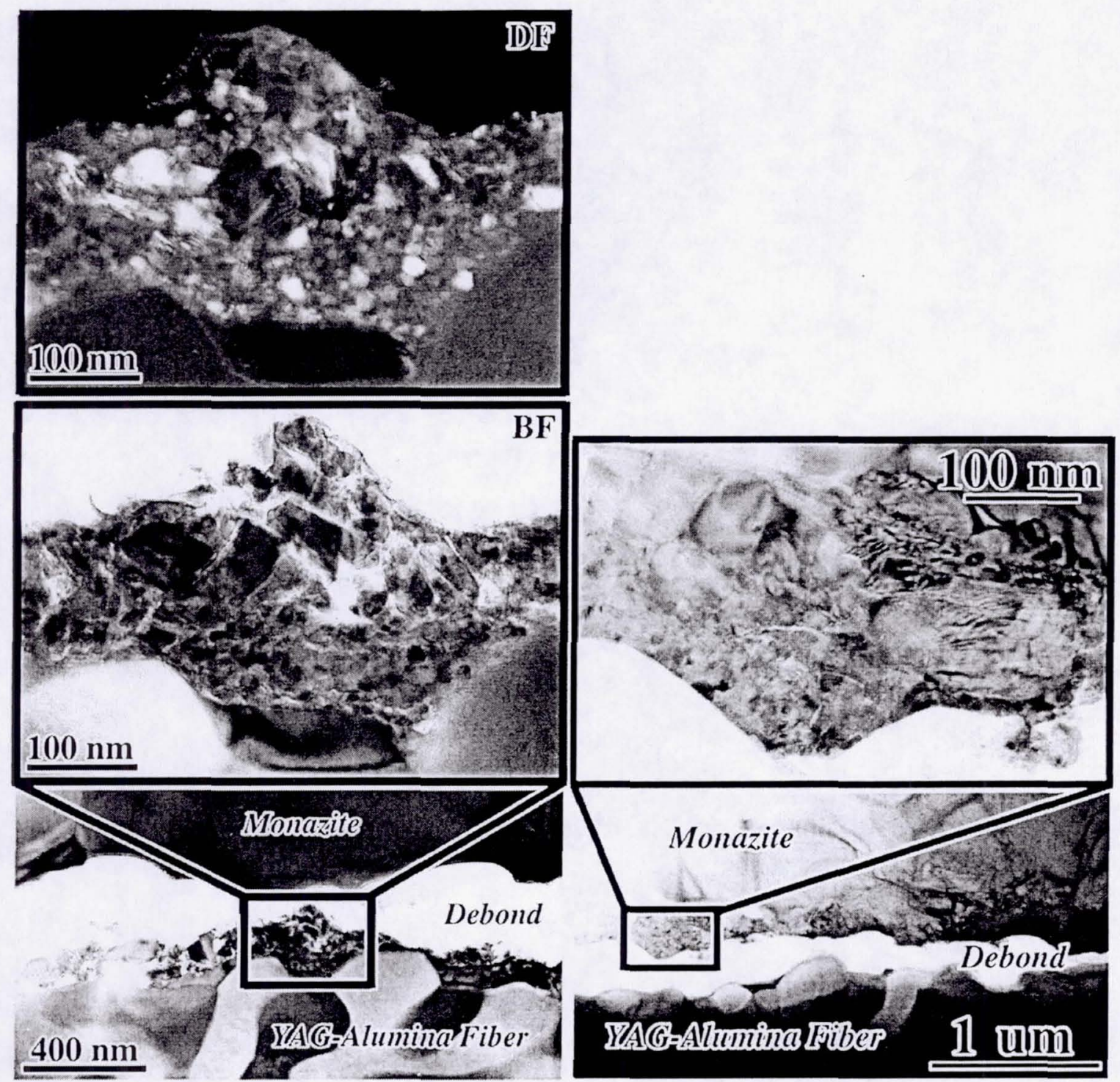

Fig. 7 TEM micrograph of monazite smeared onto $\mathrm{Al}_{2} \mathrm{O}_{3} / \mathrm{YAG}$ fiber surface. The layer adjacent to the fiber is recrystallized on a $\sim 10-20 \mathrm{~nm}$ scale. The layer over it has more porous, coarsegrained angular particles diagnostic of cataclastic flow.

Fig. 8. Intense plastic deformation and fine- scale microcracking in coating on $\mathrm{Al}_{2} \mathrm{O}_{3} / \mathrm{YAG}$ fiber. A heavily deformed ball of monazite $(\sim 100 \mathrm{~nm}$ diameter $)$ is in the debond crack in the lower right-hand corner of the high-magnification inset. 


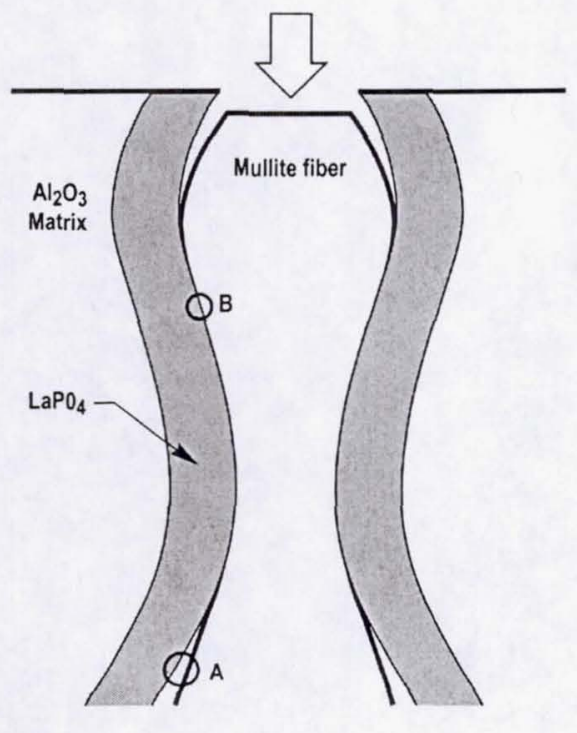

PSC0820050sol

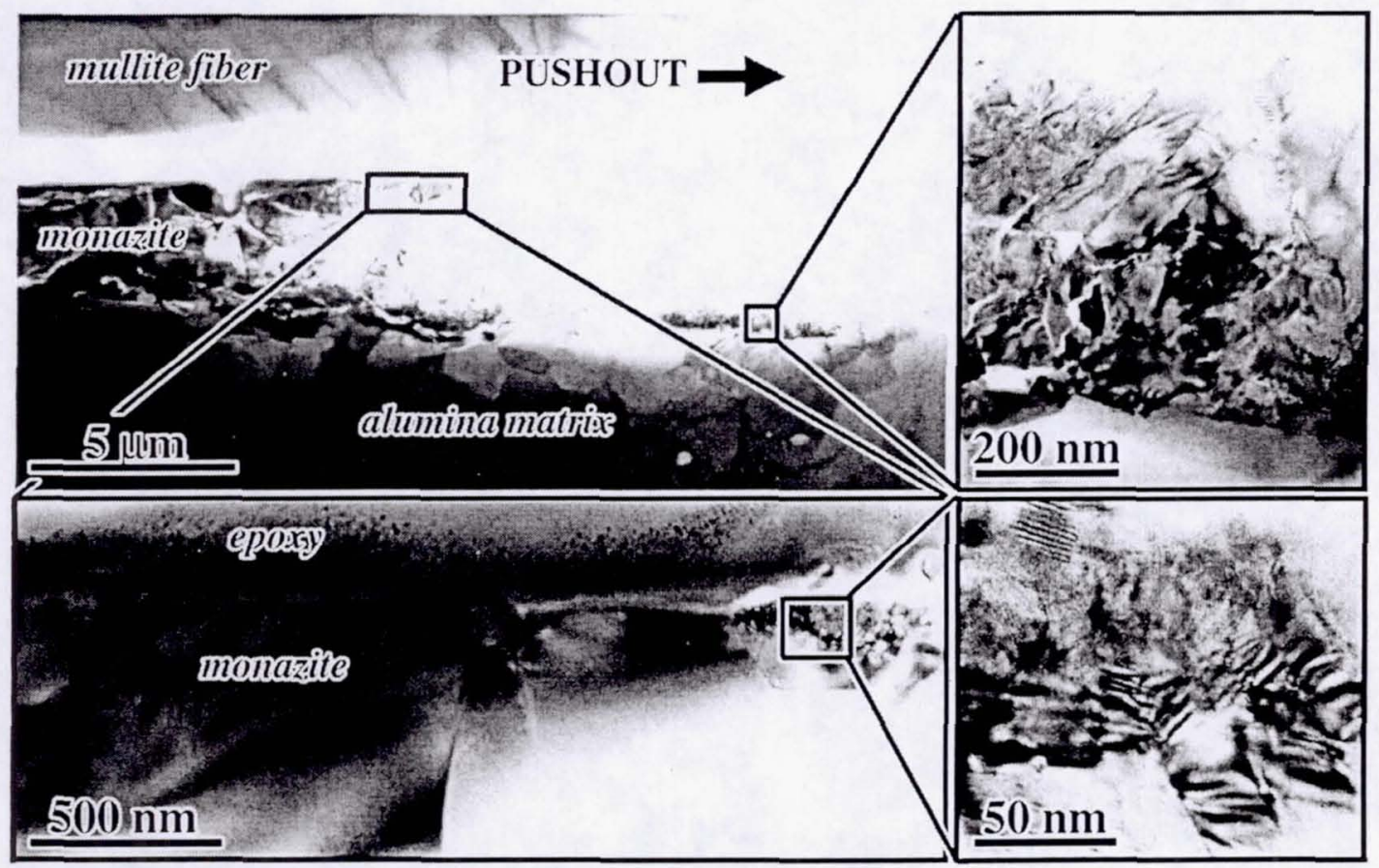

Fig 9. Schematic of fiber sliding for monazite-coated mullite fiber.

Fig. 10 Monazite coating on mullite fiber: region that was thought to have experienced tension during fiber sliding (as in Region A, Fig. 9). Monazite next to the fiber is mostly undamaged, but entire coating is cracked. Compression increases towards the right side of the micrograph. 


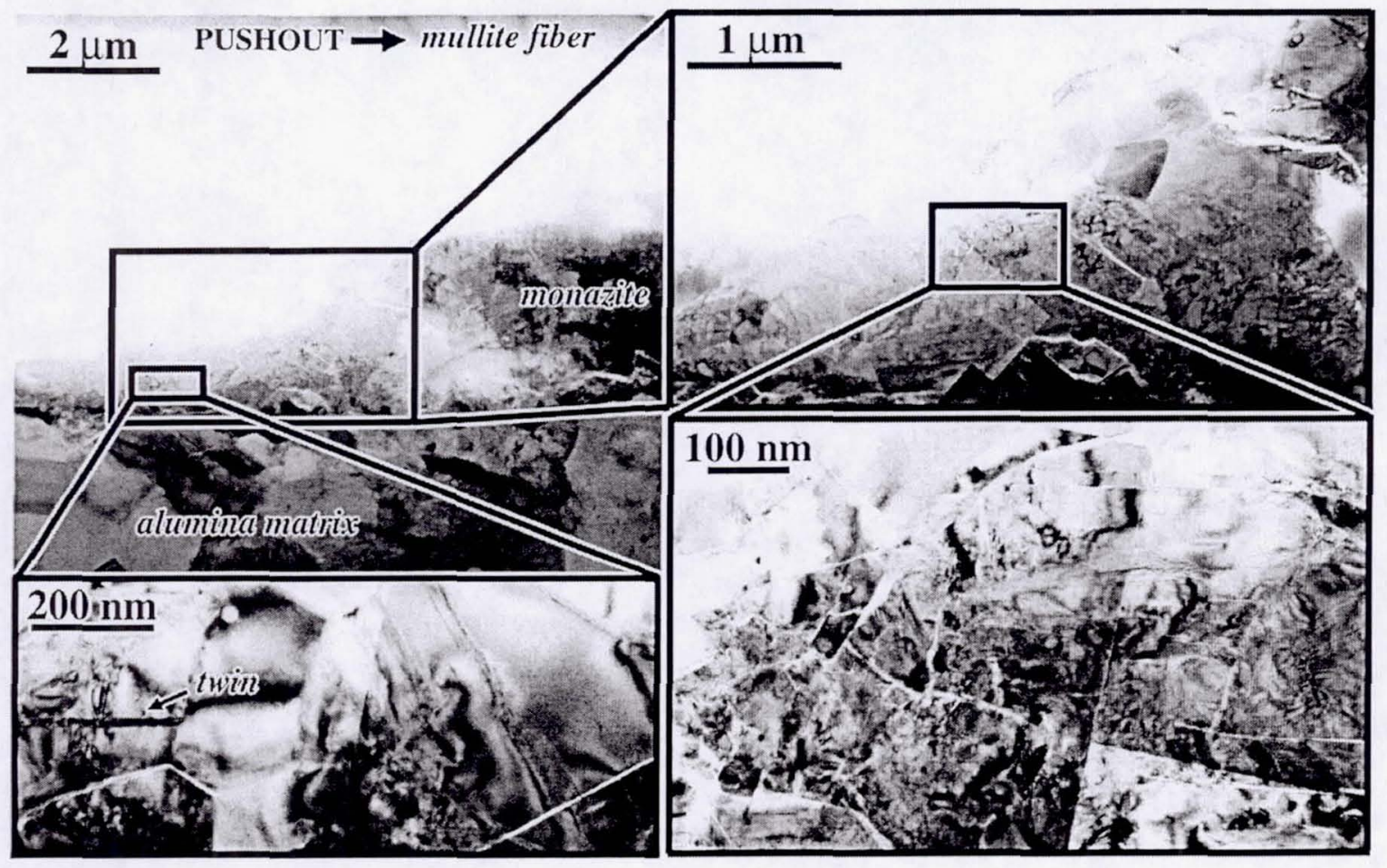

Fig. 11 Monazite coating on mullite fiber: region that was thought to have experienced compression during fiber sliding (as in Region B, Fig. 9). The coating is heavily deformed through the entire thickness, although with grain-to-grain variation. Large cracks tend to run NW - SE.

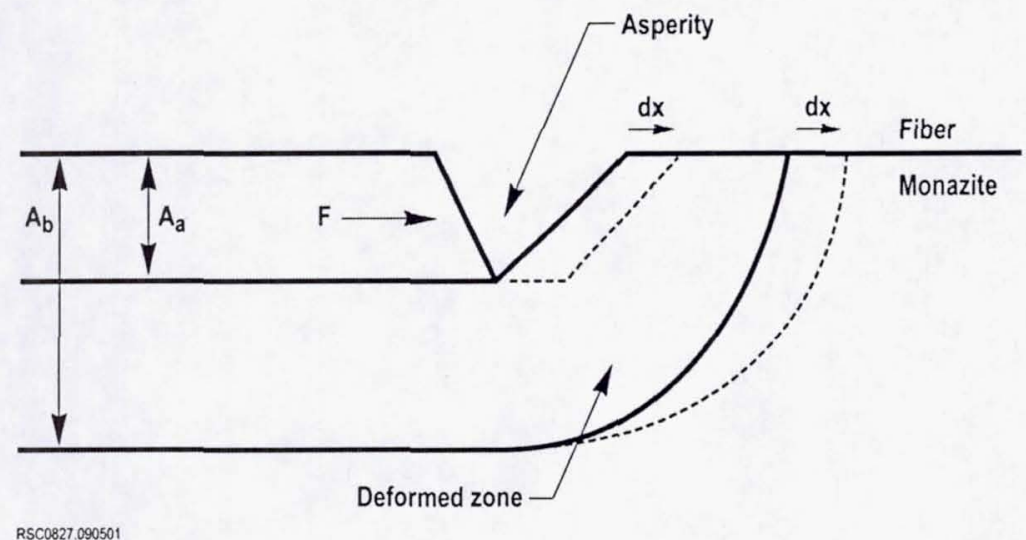

Fig. A1. Schematic showing asperity sliding and associated deformation zone. 